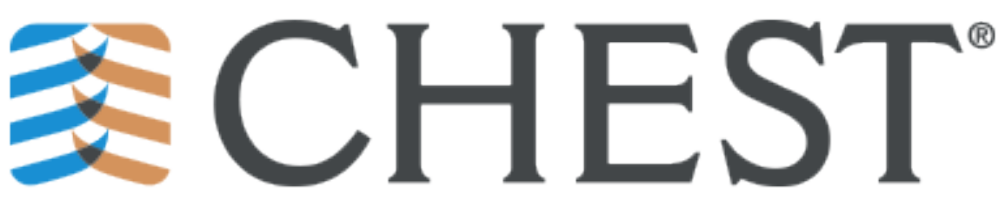

If there is Online Only content that cannot be converted to a Word processing format, you may have to click the Supplemental Files icon on the menu bar in your Reviewer Center to access.

\title{
Minimal clinically important differences for patient-reported outcome measures of fatigue in patients with COPD after pulmonary rehabilitation.
}

\begin{tabular}{|r|l|}
\hline Journal: & CHEST \\
\hline Manuscript ID & CHEST-19-2122.R1 \\
\hline Article Type: & Original Research \\
\hline Author: & $\mathrm{n} / \mathrm{a}$ \\
\hline Complete List of Authors: & $\begin{array}{l}\text { Rebelo, Patricia; University of Aveiro, Lab 3R - Respiratory Research and } \\
\text { Rehabilitation Laboratory, School of Health Sciences (ESSUA); University } \\
\text { of Aveiro, iBiMED - Institute of Biomedicine, Department of Medical } \\
\text { Sciences } \\
\text { Oliveira, Ana; West Park Healthcare Centre, Respiratory Medicine; } \\
\text { McMaster University, School of Rehabilitation Science; University of } \\
\text { Aveiro, Lab3R - Respiratory Research and Rehabilitation Laboratory, } \\
\text { School of Health Sciences (ESSUA); University of Aveiro, iBiMED - } \\
\text { Institute of Biomedicine, Department of Medical Sciences } \\
\text { Andrade, Lília; Centro Hospitalar do Baixo Vouga EPE, Pulmonology } \\
\text { Department } \\
\text { Valente, Carla; Centro Hospitalar do Baixo Vouga EPE, Pulmonology } \\
\text { Department } \\
\text { Marques, Alda; University of Aveiro, Lab 3R - Respiratory Research and } \\
\text { Rehabilitation Laboratory, School of Health Sciences (ESSUA); University } \\
\text { of Aveiro, iBiMED - Institute of Biomedicine, Department of Medical } \\
\text { Sciences }\end{array}$ \\
\hline Keywords: & $\begin{array}{l}\text { EXERCISE, Interpretability, Outcome measurement, Health Status, } \\
\text { Clinical decision-making }\end{array}$ \\
\hline & \\
\hline
\end{tabular}

\section{SCHOLARONE" Manuscripts}


AECOPD - Acute exacerbation of Chronic Obstructive Pulmonary Disease

AUC - Area under the curve

CAT - COPD Assessment Test

$\mathrm{CI}$ - Confidence interval

CIS-FS - Checklist of individual strength fatigue subscale

COPD - Chronic Obstructive Pulmonary Disease

ES - Effect size

FACIT-FS - Functional assessment of chronic illness therapy fatigue subscale

GRC - Global Rating of Change Scale

LR - Likelihood ratio

MCID - Minimal clinically important difference

MDC - Minimal detectable change

PR - Pulmonary rehabilitation

PROM - Patient-reported outcome measure

ROC - Receiver operating characteristic

SD - Standard deviation

SEM - Standard error of measure

SGRQ - St. George's Respiratory Questionnaire 
Text word count $(\max 2500): 3027$

Abstract word count ( $\max 250): 239$

Running head (of 50 characters or less): Fatigue in COPD: quantifying improvement

Minimal clinically important differences for patient-reported outcome measures of fatigue in patients with COPD after pulmonary rehabilitation.

Patrícia Rebelo, $\mathrm{MSc}^{1,2}$, Ana Oliveira, $\mathrm{PhD}^{1-4}$, Lília Andrade ${ }^{5}$, Carla Valente ${ }^{5}$, Alda Marques, $\mathrm{PhD}^{1,2}$

${ }^{1}$ Lab3R - Respiratory Research and Rehabilitation Laboratory, School of Health Sciences, University of Aveiro (ESSUA), Aveiro, Portugal

${ }^{2}$ iBiMED - Institute of Biomedicine, Department of Medical Sciences, University of Aveiro, Aveiro, Portugal

${ }^{3}$ West Park Healthcare Centre, Toronto, ON, Canada

${ }^{4}$ School of Rehabilitation Science, McMaster University, Hamilton, ON, Canada

${ }^{5}$ Pulmonology Department, Centro Hospitalar do Baixo Vouga, Aveiro

Corresponding author information: Alda Marques, ${ }^{1}$ Lab3R - Respiratory Research and Rehabilitation Laboratory, School of Health Sciences (ESSUA) and ${ }^{2}$ Institute of Biomedicine (iBiMED), University of Aveiro, Agras do Crasto - Campus Universitário de Santiago, Edifício 30, 3810-193 Aveiro, Portugal

Tel +351234372462

Email amarques@ua.pt

Conflict of interests' statement: The authors report no financial, or non-financial, conflicts of interest in this work.

Funding information: This work, was funded by Fundo Europeu de Desenvolvimento Regional (FEDER) - Comissão Diretiva do Programa Operacional Regional do Centro, by Fundação para a Ciência e Tecnologia - FCT (SAICT-POL/23926/2016, PTDC/DTPPIC/2284/2014, PTDC/SAU-SER/28806/2017, UID/BIM/04501/2019) and by Programa Operacional Competitividade e Internacionalização (COMPETE), through COMPETE 2020 (POCI-01-0145-FEDER-016701， POCI-01-0145-FEDER-007628， POCI-01-0145FEDER-028806).

\section{Notation of prior abstract publication/presentation:}

- European Respiratory Society (ERS) International Congress, $28^{\text {th }}$ September $-2^{\text {nd }}$ October 2019, Madrid, Spain

- World Confederation of Physical Therapy Congress, $10^{\text {th }}-13^{\text {th }}$ May 2019, Genève, Switzerland 


\section{ABSTRACT:}

2 Background: Fatigue is a burdensome and prevailing symptom in patients with chronic 3 obstructive pulmonary disease (COPD). Pulmonary rehabilitation (PR) improves fatigue 4 however, interpreting when such improvement is clinically relevant is challenging. Minimal 5 clinically important differences (MCIDs) for instruments assessing fatigue are warranted to 6 better tailor PR and guide clinical decisions. We estimated MCIDs for the functional 7 assessment of chronic illness therapy-fatigue subscale (FACIT-FS), the modified-FACIT8 FS and the checklist of individual strength-fatigue subscale (CIS-FS), in patients with COPD 9 after PR.

10 Methods: Data from patients with COPD who completed a 12-weeks community-based PR 11 programme were used to compute the MCIDs. The pooled MCID was estimated by 12 calculating the arithmetic weighted mean, resulting from the combination of anchor (weight13 2/3) and distribution-based (weight-1/3) methods. Anchors were patients' and 14 physiotherapists' global rating of change scale, COPD assessment test, St. George's 15 respiratory questionnaire (SGRQ) and exacerbations. To estimate MCIDs we used mean 16 change, receiver operating characteristic curves and linear regression analysis for anchor17 based approaches, and $0.5^{*}$ standard deviation, standard error of measurement 18 (SEM), 1.96*SEM and minimal detectable change for distribution-based approaches.

19 Results: Fifty-three patients with COPD (79\%male, 68.4 \pm 7.6years, FEV $148.7 \pm 17.4 \%$ predicted) 20 were used in the analysis. Exacerbations, the SGRQ-impact and the SGRQ-total scores 21 fulfilled the requirements to be used as anchors. Pooled MCIDs were 4.7 for FACIT-FS, 3.8 22 for the modified-FACIT-FS and 9.3 for the CIS-FS.

23 Conclusion: The MCIDs proposed in this study can be used by different stakeholders to 24 interpret PR effectiveness.

25 Clinical trial registration: NCT03799666 on ClinicalTrials.gov

Keywords: *Exercise *Interpretability *Outcome measurement $*$ Health status * clinical decision-making 


\section{INTRODUCTION:}

Chronic obstructive pulmonary disease (COPD) is highly symptomatic. ${ }^{1}$ Although dyspnoea is the symptom most commonly reported, ${ }^{1}$ fatigue has been recognised to affect around 50 to $70 \%$ of patients with COPD. ${ }^{2,3}$ Fatigue is a multi-dimensional and disabling symptom defined as an overwhelming feeling of tiredness and drain of energy. ${ }^{4,5}$ It negatively influences patients' physical, cognitive, psychological and social functioning, ${ }^{4,6-8}$ leads to limited daily functioning and reduced health-related quality of life. ${ }^{3,8-10}$ Fatigue severely impacts on COPD prognosis, being closely associated to exacerbations rate and an independent predictor of mortality. ${ }^{10-13}$

Pulmonary rehabilitation (PR) is a fundamental intervention to manage COPD, with known cost-effectiveness in fatigue reduction. ${ }^{1,8,14-18}$ However, the interpretation of PR effects on fatigue remains a challenge due to the lack of well-established minimal clinically important differences (MCID) of patient-reported outcome measures (PROMs) that assess fatigue. ${ }^{19-}$ ${ }^{21}$ MCIDs establish thresholds for clinical meaningfulness, i.e., determine which is the smallest change in a PROM score that will be perceived as an important improvement for the patient. 19,21,22 MCIDs for fatigue-related PROMs will establish a therapeutic threshold for PR effectiveness and guide clinical decision-making in the management of patients with COPD. ${ }^{23-25} \mathrm{~A}$ wide variety of methods can be used to estimate MCIDs, ${ }^{23,24,26-28}$ among which the following two are distinguished: anchor-based methods, which use an external criterion (e.g., self-reported opinion or clinicians judgements) to provide clinical meaning; ${ }^{27,29}$ and distribution-based methods, that add statistical significance by expressing change scores according to the sample variability and measurement precision. ${ }^{27,30}$ Although the importance of anchor-based approaches in comparison to distribution methods has been advocated, ${ }^{23,27}$ both methodologies present limitations, thus, the recommendation is to triangulate both methods. ${ }^{27,28}$

We determined the MCID of three PROMs commonly used to assess fatigue in patients with COPD, the functional assessment of chronic illness therapy fatigue subscale (FACIT-FS), ${ }^{31}$ the modified-FACIT-FS ${ }^{32}$ and the checklist of individual strength fatigue subscale (CISFS). ${ }^{4}$

\section{MATERIALS AND METHODS:}

\section{Study design and population}


This observational prospective study is integrated into a larger trial (NCT03799666), with ethical approval from the Ethics Committee for Health of the Administração Regional de Saúde do Centro (Ref. 73/2016) and from the National Committee for Data Protection (no. 7295/2016). All participants signed an informed consent.

Patients diagnosed with COPD, ${ }^{1}$ who completed a 12-weeks community-based PR programme, between January and July 2019, in 6 primary healthcare centres and in the

\section{Sciences, University of Aveiro, were included. Exclusion criteria included the presence of} other respiratory diseases or significant cardiovascular, neurological or musculoskeletal disease which limited patients' participation in PR. The PR programme consisted of exercise training sessions twice a week and education and psychosocial sessions once every two weeks, with two of them targeting specifically the management of fatigue: i) management of symptoms and strategies of energy conservation and ii) sleep disorders and management of stress and anxiety. Further information regarding the intervention and education and psychosocial contents has been previously published. ${ }^{33,34}$ Only participants who attended at least 8 of the 12-weeks of PR were included. ${ }^{1}$

A sample size of at least 50 participants is required to determine the MCID of a PROM. ${ }^{35,36}$ Since the drop-out rates during PR programmes range from 20 to $30 \%, 37,38$ we aimed to recruit 65 participants.

\section{Data collection}

Sociodemographic, anthropometric and clinical data were obtained to characterise the sample. The Charlson Comorbidity Index ${ }^{39}$ was used to score the severity of comorbid conditions. The remaining outcome measures were assessed before (T0) and after PR (T1). Impact of the disease was assessed with the COPD assessment test (CAT) ${ }^{40}$ and healthrelated quality of life with the St. George's respiratory questionnaire (SGRQ). ${ }^{41}$

The FACIT-FS is a multi-dimensional 13-item questionnaire assessing tiredness, weakness and difficulty in handling daily activities due to fatigue, over the previous 7 days. ${ }^{12,31}$ Each item has a 5-points Likert scale (from "not at all" to "very much"), and scores range from 0 to 52, with higher scores indicating less fatigue. ${ }^{31,42}$ Patients scoring below the cut-off point of 43 points were considered to have clinically relevant fatigue. ${ }^{43}$ The FACIT-FS has shown high internal consistency ${ }^{32}$ and test-retest reliability, ${ }^{44}$ and good concurrent and discriminating validity ${ }^{32,45}$ in patients with COPD. A modified version of FACIT-FS, 
94 adapted to patients with COPD, has been proposed. ${ }^{32}$ The modified-FACIT-FS has 9 items and scores range from 0 to 36 points. ${ }^{32}$

96 The CIS-FS ${ }^{4}$ was used to evaluate the fatigue experience. The CIS-FS is an 8-statements self-reported measure, with a period recall of two weeks, where each item is scored on a 7point Likert scale. ${ }^{4}$ Total scores range from 8 to 56, and 3 subgroups can be categorised: normal fatigue ( $\leq 26$ points), mild fatigue (27-35 points) and severe fatigue ( $\geq 36$ points). ${ }^{46}$

100 The CIS-FS has shown high internal consistency and test-retest reliability, good concurrent 101 and criterion validity ${ }^{46}$ and ability to detect change in subjective fatigue..$^{2,47-49}$

102 The global rating of change scale (GRC) is a simple, retrospective and numerical analogue scale $^{50}$ that asks patients to make a judgement regarding their perceived fatigue after PR and to compare it with the initial assessment. It was administered only after PR, using an 11point Likert scale ranging from -5 (much worse) to +5 (much better) (supplementary material). ${ }^{50}$

\section{Statistical analysis}

108 Data analysis was performed with IBM SPSS Statistics 24, and plots were designed with 109 GraphPad Prism 7 and MetaXL 5.3. Paired t-test were used to test significance of changes 110 in PROMs from T0 to T1. Floor and ceiling effects were checked and deemed inexistent if 111 less than $15 \%$ of the patients scored at the bottom or top of the questionnaires. ${ }^{51}$ Outliers 112 were checked, i.e., inspection of extreme points in plotted graphs from the studied variables, 113 and excluded if present. ${ }^{52}$

114 MCIDs were established through the combination of anchor-based and distribution-based 115 methods for the FACIT-FS, modified-FACIT-FS and CIS-FS. ${ }^{24,27}$

\section{Anchor-based methods}

117 The following measures were explored for their adequacy to be used as anchors:

118 i) Patients referencing: the GRC was used to classify patients' perception of change in 119 fatigue. Significant changes were considered for the GRC higher than $2 .{ }^{50}$

ii) Physiotherapists referencing: the GRC was used to ask the physiotherapists running the PR programmes about their perception regarding patients' changes in fatigue. Significant changes were considered for the GRC higher than $2 .{ }^{50}$ 
123

124

125

126

127

128

129

130

131

132

133

134

135

136

137

138

139

140

141

142

143

144

145

146

147

148

149

150

151

152

iii) Questionnaire referencing: changes in CAT and SGRQ were used as external criterions to determine the CIS-FS and FACIT-FS MCIDs. The MCIDs for the CAT ( 2 points $)^{53}$ and for the SGRQ (4 points) ${ }^{54}$ were used to distinguish between patients who improved from those who did not improve their fatigue symptoms.

iv) Criterion referencing: AECOPD are considered major health events ${ }^{1}$ and are correlated to worse PROM scores, thus, their occurrence during PR was used as an anchor. $^{25}$

Correlations between the potential anchors and each fatigue-related PROM were explored using Pearson or point-biserial correlation coefficients. For patients, physiotherapists and questionnaire referencing, significant and moderate correlations $(r \geq 0.3)$ were established as criteria to proceed with the calculation of the MCIDs using anchor-based methods. ${ }^{27}$ Then, three statistical methods were used to compute the MCID: i) mean change in the PROM score (between T1 and T0) for patients who reached the anchor MCID;22,24 ii) receiver operating characteristic (ROC) curves and the corresponding likelihood ratio (LR) (interpreted according to $\mathrm{McGee}$ ), ${ }^{55}$ calculated with the dichotomous variable, i.e., those who achieved or not the MCID of the anchor [an area under the curve (AUC) was considered adequate if statistically significant and greater than 0.7 ; the optimal cut-off point was set as the point where specificity and sensitivity were both optimised, i.e., the closest point to the left corner $]^{55}$ and iii) linear regression analysis, using the Enter method, where the change in the fatigue PROMs was used as the dependent variable, and the change score of the anchor was considered the independent variable.

Regarding criterion referencing, the presence of significant differences in fatigue baseline scores between patients who experienced an exacerbation and those who did not was the criteria to proceed with the MCID calculation. Independent t-tests were used to explore differences and when present, the absolute difference was considered the $\mathrm{MCID}^{25,56}$ Afterwards, ROC statistics were used to test the PROMs discriminating ability to anticipate the occurrence of an AECOPD.

$\underline{\text { Distribution-based methods }}$

The distribution-based methods used to determine the MCID were:

i) $\quad 0.5$ times standard deviation $(\mathrm{SD})$ at the baseline; ${ }^{26}$ 
153

154

155

156

157

158

159

160

161

162

163

164

165

166

167

168

169

170

171

172

173

174

175

176

177

178

179

180

181

ii) standard error of measurement (SEM), calculated as $\mathrm{SEM}=\mathrm{SD}_{\text {baseline }} \sqrt{ }(1-\mathrm{r})$, where $\mathrm{r}$ is the test-retest reliability coefficient; ${ }^{21}$

iii) $\quad 1.96$ times SEM;;23,28

iv) minimal detectable change $(\mathrm{MDC}),{ }^{26,57}$ calculated as $\mathrm{MDC}=1.96 * \mathrm{SEM}^{*} \sqrt{ } 2$;

v) effect size (ES) through $\mathrm{ES}=\left(\mathrm{mean}_{\mathrm{afterPR}}-\mathrm{mean}_{\text {baseline }}\right) /$ $\sqrt{\left(\mathrm{SD}_{\mathrm{afterPR}}^{2}+\mathrm{SD}_{\text {baseline }}^{2}\right) / 2}$. The ES thresholds were $\geq 0.2$ for small, $\geq 0.5$ for medium and $\geq 0.8$ for large..$^{57}$

\section{$\underline{\text { Pooled MCID }}$}

There are no guidelines on how to weight anchor- and distribution-based approaches, therefore, based on the authors' best judgement and on previous work, ${ }^{58,59}$ we decided to attribute $2 / 3$ to anchor-based and $1 / 3$ to distribution-based methods. To pool the final MCID we calculated the arithmetic weighted mean. The MCIDs generated from the different methods were entered into the MetaXL 5.3 to create the MCIDs' plots. The percentage of change of the pooled MCID in relation to the fatigue-related PROMs was also calculated. Previous studies have suggested that MCIDs which fell within the range of 6 to $10 \%$ of the total score ${ }^{24}$ correspond to the desirable ES for MCID, i.e., 0.2 to $0.5 .{ }^{24,27,57}$ The ES derived from the pooled MCID were calculated using the ESformula: $\mathrm{MCID}_{\mathrm{ES}}=$ $\mathrm{MCID}_{\text {pooled }} / \sqrt{\left(\mathrm{SD}_{\text {afterPR }}^{2}+\mathrm{SD}_{\text {baseline }}^{2}\right) / 2}$.

\section{RESULTS:}

A flow diagram of the recruited and included patients is provided in Figure 1. (Please insert Figure 1 here)

After outliers' assessment, five participants were excluded since in boxplot analysis, they presented extreme scores in FACIT-FS and SGRQ-total change scores. Baseline characteristics of the included sample and of the outliers were not statistically different ( $>0.05)$. Included patients and drop-outs presented similar baseline characteristics (Table $1)$.

(Please insert Table 1 here)

After PR, significant improvements were found in all PROMs (Table 2): 86.8\% of participants perceived improvements in their fatigue (GRC: 3.0 [2.0-4.0]) and 

physiotherapists also considered that $86.8 \%$ of patients improved (3.0, [2.0-4.0]). No ceiling/floor effects were found for the FACIT-FS, modified-FACIT-FS and CIS-FS.

(Please insert Table 2 here)

\section{Minimal clinically important differences}

\section{$\underline{\text { Anchor-based methods }}$}

187 Changes in the FACIT-FS and modified-FACIT-FS correlated significantly and moderatly 188 with changes in the SGRQ-total $(r=-0.330 ; r=-0.439)$, -impact scores $(r=-0.409 ; r=-0.474)$ 189 and with AECOPD $\left(\mathrm{r}_{\mathrm{pb}}=-0.277 ; \mathrm{r}_{\mathrm{pb}}=-0.274\right)$. A significant correlation between changes in 190 modified-FACIT-FS and SGRQ-ativities scores was also present, however, it was not 191 considered since it was inferior to $0.3(\mathrm{r}=-0.288)$. Changes in the CIS-20 FS correlated only with AECOPD $\left(\mathrm{r}_{\mathrm{pb}}=0.323\right)$, therefore, the remaining anchors were not further analysed. All correlations are presented in e-Table 1.

\section{Questionnaire referencing}

MCIDs for the FACIT-FS derived from the mean change methods were 5.7 points using the SGRQ-impact and 4.9 points using the SGRQ-total whereas for the modified-FACIT-FS were 4.4 points using SGRQ-impact and 3.9 using SGRQ-total (Table 3). Mean change results for all the explored anchors can be found in e-Table 2 and e-Table 3.

199 The AUCs generated for either FACIT-FS and modified-FACIT-FS using the SGRQimpact/total did not fulfill the requirements, thus, ROC statistics were not used.

Using linear regression, the estimated MCIDs for the FACIT-FS were 3.4 (SGRQ-impact) and 3.2 (SGRQ-total) points and for the modified-FACIT-FS were 2.3 points using SGRQimpact and 1.9 points using SGRQ-total (Figure 2).

(Please insert Figure 2 here)

\section{Criterion Referencing}

Mean change method applied for criterion referencing yielded a MCID of 6.4 (95\%CI 1.2 to 11.6; $\mathrm{p}=0.044$ ) points for the FACIT-FS; of 4.7 (95\%CI 0.1 to $9.3 ; \mathrm{p}=0.047$ ) points for the modified-FACIT-FS; and of 9.6 points $(95 \% \mathrm{CI} 2.5$ to $16.0 ; \mathrm{p}=0.018)$ for CIS-FS (e- 
210 The AUCs generated for all fatigue PROMs were able to distinguish between patients who

211 experienced an AECOPD and those who did not (FACIT-FS: AUC $=0.71 ; 95 \%$ CI 0.58 to $2120.85 ; \mathrm{p}=0.021 /$ modified-FACIT-FS: $\mathrm{AUC}=0.73 ; 95 \% \mathrm{CI} 0.59$ to $0.86 ; \mathrm{p}=0.015 / \mathrm{CIS}-\mathrm{FS}$ : $213 \mathrm{AUC}=0.72 ; 95 \% \mathrm{CI} 0.57$ to $0.87 ; \mathrm{p}=0.019$ )(e-Figure 1 ). According to the ROC analysis, 214 patients scoring below 32 points on the FACIT-FS or above 43.5 points on the CIS-FS had 215 a LR of 2.2 (sensitivity $=68 \%$; specificity $=69 \%$ ). Cut-off point found for the modified216 FACIT-FS was 19.5 points, with a LR of 2.5 (sensitivity=73\%; specificity $=69 \%$ ).

217 Distribution-based methods

218 Distribution-based methods for the FACIT-FS, modified-FACIT-FS and CIS-FS are 219 presented in Table 3.

$220 \quad$ Pooled MCID

221 Pooled MCIDs were 4.7 points for the FACIT-FS, 3.8 for the modified-FACIT-FS and 9.3 222 points for CIS-FS (Figure 3). Overall MCID pooled statistics are presented in Table 3.

223 (Please insert Figure 3 here)

224 (Please insert Table 3 here)

225 DISCUSSION:

226 This study found pooled MCIDs of 4.7 points for the FACIT-FS, 3.8 points for the modified227 FACIT-FS and 9.3 points for CIS-FS, following a PR programme in patients with COPD.

228 Nearly $80 \%$ of our sample reported fatigue symptoms, surpassing the 50 to $70 \%$ reported in 229 previous literature. ${ }^{2,3,11,60}$ These findings call for attention to the tremendous impact and 230 burden of fatigue in COPD, emphasising the importance of its routine assessment and the 231 need for tailoring therapies to target fatigue. Our results showed significant improvements 232 in FACIT-FS, modified-FACIT-FS and CIS-FS following a community-based-PR 233 programme, highlighting the effectiveness and the key role of this comprehensive 234 intervention in managing fatigue. . $^{2,16,18}$

235 MCIDs are recognised to be disease-specific ${ }^{23}$ and, to our best knowledge, this is the first 236 study to establish MCIDs for both FACIT-FS versions and CIS-FS in patients with COPD. 237 For the original-FACIT-FS, the MCID has been previously determined in other populations, 238 with our estimation being similar to the one reported for rheumatoid arthritis (i.e., 3-4 239 points), ${ }^{61}$ but smaller than the estimated for the systemic lupus erythematosus (i.e., 5.9 
240 points). ${ }^{62}$ These differences are likely to be explained by the dissimilarities among 241 populations and methodologies (longitudinal and within-patient differences vs. crosssectional and between patient-differences). Although a MCID of 10 points has been reported for the CIS-FS, ${ }^{2}$ no information, or reference, regarding its calculation is provided limiting comparisons between studies.

MCIDs were computed using different approaches and integrating a wide range of anchorand distribution-based methods. It is known that MDC yield large estimates and tend to overestimate MCIDs. ${ }^{23,63}$ Previous research have classified MDC as a benchmark for moderate to large change, warning that MCIDs could be smaller than MDC. ${ }^{23,63}$ These discrepancies enhance the need to combine anchor-based methods (weighting 2/3), which provide clinical meaning, and distribution-based methods (weight $1 / 3$ ), which add statistical significance, ${ }^{23,27}$ as previously recommended. ${ }^{24,27}$

Within the multiple anchor-based approaches used, only the SGRQ and the occurrence of AECOPD fulfilled the criterion to proceed with the MCID calculation, with the latter yielding larger estimations. Regarding either patients' or physiotherapists' GRC, it is noticeable that most patients/physiotherapists perceived improvements in fatigue, thus the variability of data was reduced, which is known to limit the power of correlations. ${ }^{64}$ Moreover, another hypothetical reason for the lack of correlations is the well-known recall and administration bias associated to the GRC. ${ }^{24,50,65}$ Fatigue is a complex, multifaceted and dynamic phenomenon, ${ }^{5}$ and PROMs focus specifically on the perceived fatigability, thus, do not fully portray fatigue. This complexity might also have impacted our correlations. Disparities among physiotherapists' GRC and the fatigue PROMs sustain the poor physician-patient concordance previously stated. ${ }^{66}$

The impact of fatigue on health status and quality of life is irrefutable. . $^{210,11,32}$ Previous associations between these outcomes ${ }^{2,32}$ highlight the importance of the SGRQ to determine fatigue-related MCIDs. The absence of correlations among the CIS-FS and the SGRQ dimensions might be explained by the conceptual differences between the fatigue PROMs. While the CIS-FS focuses specifically on the subjective experience of fatigue, ${ }^{4}$ FACIT-FS integrates two components of fatigue: experience of fatigue and impact of fatigue, ${ }^{67}$ probably, the latter is more intimately related to the SGRQ impact-dimension and consequently, to the total-dimension. ${ }^{32}$ CAT assesses several respiratory symptoms, and only one item is directly related to fatigue (energy). Instead of the CAT-total score, which 
272 failed to capture changes in fatigue, it would have been interesting to use as an anchor the

273 CAT-energy question. However, this was not possible, as the MCID for single CAT-items 274 is not established.

275 Similar to previous research, ${ }^{11,12}$ our study, further established the role of fatigue as a 276 prognostic measure for AECOPD, showing that patients scoring below 32 points on the 277 FACIT-FS, below 19.5 points on the modified-FACIT-FS and over 43.5 on the CIS-FS have 278 around 15\% increased probability of having and exacerbation (LR from 2.2 to 2.5). ${ }^{55}$ 279 According to our results, all fatigue PROMs used have similar prediction abilities to 280 distinguish between patients who experienced an AECOPD from those who did not. Thus, 281 these tree questionnaires seem to be equally valuable to predict a patient's exacerbation risk 282 and to adjust the PR programme accordingly (e.g., by further enhancing the education on 283 prevention of exacerbations). ${ }^{68}$

284 Nevertheless, this study also presents some limitations that should be acknowledged. First, 285 the PROMs used as referencing questionnaires, i.e., CAT and SGRQ, do not assess fatigue 286 specifically. To the authors' best knowledge, the chronic respiratory questionnaire is the 287 only PROM that specifically targets fatigue and has a MCID established for patients with 288 COPD, ${ }^{69}$ however it could not be used in this study, as it is not culturally adapted for the 289 Portuguese population. Second, our sample was mainly composed by GOLD B patients, 290 therefore, the external validity of our study might be reduced. MCIDs should correspond to 291 a 6 to $10 \%$ change in the PROMs scale and to an ES between 0.2 to $0.5 . .^{24,27,57}$ The MCID 292 found for CIS-FS corresponded to an ES of 0.7 and $19 \%$ change, thus, it may have been 293 overestimated. It is worth noting that, even if nor ceiling or floor effects were present, our 294 sample presented high baseline levels of fatigue, leading to greater room for improvement 295 with treatment, and thus higher MCIDs. ${ }^{23,24,26,70}$ The fact that only the criterion anchor and 296 distribution-based methods were used to compute the MCID for CIS-FS, could have also 297 contributed to overestimate the result. Our overall sample size was not enough to perform 298 sub-analysis according to baseline fatigue or disease severity. This study included 299 exclusively the physiotherapists GRC, thus providing a limited insight into patients' fatigue, 300 as PR is a multidisciplinary intervention. Future studies including a Delphi Method would 301 be useful to integrate different stakeholders' perspectives. ${ }^{27} \mathrm{~A}$ consensus between 302 worldwide experts in MCIDs would be extremely helpful to confidently establish the 303 weights assigned to either anchor- and distribution-based approaches. More studies with 304 larger samples are required to control for these factors and further validate our estimations. 


\section{CONCLUSIONS:}

306 The present study determined that changes of 4.7 on the FACIT-FS, 3.8 on the modified-

307 FACIT-FS and 9.3 on the CIS-FS represent clinically relevant improvements in fatigue after 308 PR in patients with COPD. These MCIDs should be interpreted accordingly to each patient 309 specificities and incorporated into clinical practice to guide different stakeholders in the 310 decision-making process.

\section{ACKNOWLEDGEMENTS:}

312 Authors' contributions: AM obtained the funding, had full access to all data in the study 313 and takes responsibility for the data and the accuracy of data analysis, including and 314 especially any adverse effects. AM and AO conceived the idea. All authors contributed to 315 the design and interpretation of data. PR, AO, LA and CV contributed to data acquisition. 316 PR performed the analysis and drafted the paper. All authors critically revised the 317 manuscript and approved the final version.

318 Financial/ nonfinancial disclosures: none declared

319 Role of sponsors: The sponsors had no role in the design of the study, the collection and 320 analysis of the data, or the preparation of the manuscript.

321 Other contributions: The authors would like to thank Cátia Paixão, Sara Miranda, Ana 322 Alves and Liliana Santos for their contribution in data collection and implementation of the 323 pulmonary rehabilitation programmes.

\section{REFERENCES (70/75):}

325 1. Global Initiative for Chronic Obstructive Lung Disease. Global Strategy for the 326 Diagnosis, Management, and Prevention of Chronic Obstructive Pulmonary Disease (2019 327 Report). 2019.

328 2. Peters JB, Heijdra YF, Daudey L, Boer LM, Molema J, Dekhuijzen PR, et al. Course 329 of normal and abnormal fatigue in patients with chronic obstructive pulmonary disease, and 330 its relationship with domains of health status. Patient education and counseling. $331 \quad 2011 ; 85(2): 281-5$.

332 3. Spruit MA, Vercoulen JH, Sprangers MA, Wouters EF. Fatigue in COPD: an 333 important yet ignored symptom. The Lancet Respiratory Medicine. 2017;5(7):542-4. 
334 4. Vercoulen JH, Swanink CM, Fennis JF, Galama JM, van der Meer JW, Bleijenberg

335 G. Dimensional assessment of chronic fatigue syndrome. Journal of psychosomatic research. $336 \quad 1994 ; 38(5): 383-92$.

337 5. Gruet M. Fatigue in Chronic Respiratory Diseases: Theoretical Framework and 338 Implications For Real-Life Performance and Rehabilitation. Frontiers in physiology. 2018;9.

339 6. Ream E, Richardson A. Fatigue in patients with cancer and chronic obstructive 340 airways disease: a phenomenological enquiry. International journal of nursing studies. $341 \quad 1997 ; 34(1): 44-53$.

342 7. Beurskens AJ, Bültmann U, Kant I, Vercoulen JH, Bleijenberg G, Swaen GM. 343 Fatigue among working people: validity of a questionnaire measure. Occupational and 344 environmental medicine. 2000;57(5):353-7.

345 8. Kouijzer M, Brusse-Keizer M, Bode C. COPD-related fatigue: Impact on daily life 346 and treatment opportunities from the patient's perspective. Respiratory Medicine. 2018. $347 \quad 141: 47-51$.

348 9. Small S, Lamb M. Fatigue in chronic illness: the experience of individuals with 349 chronic obstructive pulmonary disease and with asthma. Journal of advanced nursing. $350 \quad 1999 ; 30(2): 469-78$.

351 10. Stridsman C, Skär L, Hedman L, R^nmark E, Lindberg A. Fatigue affects health 352 status and predicts mortality among subjects with COPD: report from the population-based 353 OLIN COPD study. COPD: Journal of Chronic Obstructive Pulmonary Disease. 354 2015;12(2):199-206.

355 11. Baghai-Ravary R, Quint JK, Goldring JJ, Hurst JR, Donaldson GC, Wedzicha JA. 356 Determinants and impact of fatigue in patients with chronic obstructive pulmonary disease. 357 Respiratory medicine. 2009;103(2):216-23.

358 12. Antoniu SA, Ungureanu D. Measuring fatigue as a symptom in COPD: from 359 descriptors and questionnaires to the importance of the problem. Chronic respiratory disease. $360 \quad 2015 ; 12(3): 179-88$.

361 13. Paddison JS, Effing TW, Quinn S, Frith PA. Fatigue in COPD: association with 362 functional status and hospitalisations. European Respiratory Journal. 2013;41(3):565-70. 
363 14. McCarthy B, Casey D, Devane D, Murphy K, Murphy E, Lacasse Y. Pulmonary

364 rehabilitation for chronic obstructive pulmonary disease. Cochrane Database of Systematic 365 Reviews.2015; 23;(2):CD003793.

366 15. Spruit MA, Singh SJ, Garvey C, ZuWallack R, Nici L, Rochester C, et al. An official 367 American Thoracic Society/European Respiratory Society statement: key concepts and 368 advances in pulmonary rehabilitation. American journal of respiratory and critical care 369 medicine. 2013;188(8):e13-e64.

370 16. Payne C, Wiffen PJ, Martin S. Interventions for fatigue and weight loss in adults 371 with advanced progressive illness. Cochrane Database of Systematic Reviews. $372 \quad 2012 ; 1: C D 008427$.

373 17. Lewko A, Bidgood PL, Jewell A, Garrod R. Evaluation of multidimensional COPD374 related subjective fatigue following a pulmonary rehabilitation programme. Respiratory 375 medicine. 2014;108(1):95-102.

376 18. Van Herck M, Antons J, Vercoulen JH, Goërtz YM, Ebadi Z, Burtin C, et al. 377 Pulmonary Rehabilitation Reduces Subjective Fatigue in COPD: A Responder Analysis. 378 Journal of clinical medicine. 2019;8(8):1264.

379 19. Johnston BC, Ebrahim S, Carrasco-Labra A, Furukawa TA, Patrick DL, Crawford 380 MW, et al. Minimally important difference estimates and methods: a protocol. BMJ open. $381 \quad 2015 ; 5(10): \mathrm{e} 007953$.

382 20. Cook CE. Clinimetrics corner: the minimal clinically important change score 383 (MCID): a necessary pretense. Journal of Manual \& Manipulative Therapy. 384 2008;16(4):82E-3E.

385 21. Guyatt GH, Osoba D, Wu AW, Wyrwich KW, Norman GR, editors. Methods to 386 explain the clinical significance of health status measures. Mayo Clinic Proceedings. 2002; 387 77(4):371-83

388 22. Jaeschke R, Singer J, Guyatt GH. Measurement of health status: ascertaining the 389 minimal clinically important difference. Controlled clinical trials. 1989;10(4):407-15.

390 23. Wright A, Hannon J, Hegedus EJ, Kavchak AE. Clinimetrics corner: a closer look at 391 the minimal clinically important difference (MCID). Journal of Manual \& Manipulative 392 Therapy. 2012;20(3):160-6. 
393 24. Angst F, Aeschlimann A, Angst J. The minimal clinically important difference raised 394 the significance of outcome effects above the statistical level, with methodological 395 implications for future studies. Journal of clinical epidemiology. 2017;82:128-36.

396 25. Jones P. Interpreting thresholds for a clinically significant change in health status in 397 asthma and COPD. European Respiratory Journal. 2002;19(3):398-404.

398 26. Copay AG, Subach BR, Glassman SD, Polly DW, Schuler TC. Understanding the 399 minimum clinically important difference: a review of concepts and methods. The Spine 400 Journal. 2007;7(5):541-6.

401 27. Revicki D, Hays RD, Cella D, Sloan J. Recommended methods for determining 402 responsiveness and minimally important differences for patient-reported outcomes. Journal 403 of clinical epidemiology. 2008;61(2):102-9.

404 28. Rai SK, Yazdany J, Fortin PR, Aviña-Zubieta JA. Approaches for estimating 405 minimal clinically important differences in systemic lupus erythematosus. Arthritis research 406 \& therapy. 2015;17(1):143.

407 29. Haley SM, Fragala-Pinkham MA. Interpreting change scores of tests and measures 408 used in physical therapy. Physical therapy. 2006;86(5):735-43.

409 30. Norman GR, Sloan JA, Wyrwich KW. Interpretation of changes in health-related 410 quality of life: the remarkable universality of half a standard deviation. Medical care. $411 \quad 2003 ; 41(5): 582-92$.

412 31. Webster K, Cella D, Yost K. The F unctional A ssessment of C hronic I llness T 413 herapy (FACIT) Measurement System: properties, applications, and interpretation. Health 414 and quality of life outcomes. 2003;1(1):79.

415 32. Al-Shair K, Muellerova H, Yorke J, Rennard SI, Wouters EF, Hanania NA, et al. 416 Examining fatigue in COPD: development, validity and reliability of a modified version of 417 FACIT-F scale. Health and quality of life outcomes. 2012;10(1):100.

418 33. Marques A, Jácome C, Rebelo P, Paixão C, Oliveira A, Cruz J, et al. Improving 419 access to community-based pulmonary rehabilitation: 3R protocol for real-world settings 420 with cost-benefit analysis. BMC Public Health. 2019;19(676).

421 34. Laboratório de Investigação e Reabilitação Respiratória (Lab3R). Plataforma de 422 Reabilitação Respiratória em Rede. 2018. Available from: http://3r.web.ua.pt/. 
35. Terwee CB, Bot SD, de Boer MR, van der Windt DA, Knol DL, Dekker J, et al. Quality criteria were proposed for measurement properties of health status questionnaires. Journal of clinical epidemiology. 2007;60(1):34-42.

36. Mokkink LB, Prinsen CA, Patrick DL, Alonso J, Bouter LM, de Vet HC, et al. COSMIN Study Design checklist for Patient-reported outcome measurement instruments. 2019.

430 37. Fischer MJ, Scharloo M, Abbink JJ, van`t Hul AJ, van Ranst D, Rudolphus A, et al. 431 Drop-out and attendance in pulmonary rehabilitation: the role of clinical and psychosocial variables. Respiratory medicine. 2009;103(10):1564-71.

433 38. Keating A, Lee A, Holland AE. What prevents people with chronic obstructive 434 pulmonary disease from attending pulmonary rehabilitation? A systematic review. Chronic 435 respiratory disease. 2011;8(2):89-99.

39. Charlson ME, Pompei P, Ales KL, MacKenzie CR. A new method of classifying prognostic comorbidity in longitudinal studies: development and validation. Journal of chronic diseases. 1987;40(5):373-83.

40. Jones P, Harding G, Berry P, Wiklund I, Chen W, Leidy NK. Development and first validation of the COPD Assessment Test. European Respiratory Journal. 2009;34(3):64854.

442 41. Jones PW, Quirk FH, Baveystock CM, Littlejohns P. A self-complete measure of 443 health status for chronic airflow limitation. American Review of Respiratory Disease. 444 1992;145(6):1321-7.

42. Elbers RG, Rietberg MB, van Wegen EE, Verhoef J, Kramer SF, Terwee CB, et al. Self-report fatigue questionnaires in multiple sclerosis, Parkinson's disease and stroke: a

448 43. Cella D, Lai Js, Chang CH, Peterman A, Slavin M. Fatigue in cancer patients 449 compared with fatigue in the general United States population. Cancer. 2002;94(2):528-38.

450 44. Anderson WH, Ha JW, Couper DJ, O’Neal WK, Barr RG, Bleecker ER, et al. 451 Variability in objective and subjective measures affects baseline values in studies of patients 452 with COPD. PloS one. 2017;12(9):e0184606. 
453 45. Al-Shair K, Müllerova H, Locantore N, Hanania N, Sharafkhaneh A, Wouters E, et 454 al. Fatigue components in COPD patients and controls using the FACIT-F scale; data from 455 ECLIPSE study. European Respiratory Journal; 2011;38:3624.

456 46. Worm-Smeitink M, Gielissen M, Bloot L, van Laarhoven H, van Engelen B, van 457 Riel P, et al. The assessment of fatigue: Psychometric qualities and norms for the Checklist 458 individual strength. Journal of psychosomatic research. 2017;98:40-6.

459 47. van Koulil S, Kraaimaat FW, van Lankveld W, van Riel PL, Evers AW. A patient's 460 perspective on multidisciplinary treatment gain for fibromyalgia: An indicator for pre - post 461 treatment effects? Arthritis Care \& Research. 2009;61(12):1626-32.

462 48. Panitz S, Kornhuber M, Hanisch F. The checklist individual strength (CIS20 - R) in 463 patients with amyotrophic lateral sclerosis-A longitudinal study. Acta Neurologica 464 Scandinavica. 2015;131(6):372-80.

465 49. Evers AW, Kraaimaat FW, van Riel PL, de Jong AJ. Tailored cognitive-behavioral 466 therapy in early rheumatoid arthritis for patients at risk: a randomized controlled trial. Pain. $467 \quad 2002 ; 100(1-2): 141-53$.

468 50. Kamper SJ, Maher CG, Mackay G. Global rating of change scales: a review of 469 strengths and weaknesses and considerations for design. Journal of Manual \& Manipulative 470 Therapy. 2009;17(3):163-70.

471 51. McHorney CA, Tarlov AR. Individual-patient monitoring in clinical practice: are 472 available health status surveys adequate? Quality of Life Research. 1995;4(4):293-307.

473 52. Aggarwal R, Ranganathan P. Common pitfalls in statistical analysis: The use of 474 correlation techniques. Perspectives in clinical research. 2016;7(4):187.

475 53. Kon SS, Canavan JL, Jones SE, Nolan CM, Clark AL, Dickson MJ, et al. Minimum 476 clinically important difference for the COPD Assessment Test: a prospective analysis. The 477 lancet Respiratory medicine. 2014;2(3):195-203.

478 54. Jones PW. St. George's respiratory questionnaire: MCID. COPD: Journal of Chronic 479 Obstructive Pulmonary Disease. 2005;2(1):75-9.

480 55. McGee S. Simplifying likelihood ratios. Journal of general internal medicine. $481 \quad 2002 ; 17(8): 647-50$. 
56. Alma H, De Jong C, Jelusic D, Wittmann M, Schuler M, Flokstra-de Blok B, et al. 483 Health status instruments for patients with COPD in pulmonary rehabilitation: defining a 484 minimal clinically important difference. NPJ primary care respiratory medicine. 2016;26:16041.

486

57. Cohen J. A power primer. Psychological bulletin. 1992;112(1):155.

487

58. Oliveira A, Machado A, Marques A. Minimal Important and Detectable Differences of Respiratory Measures in Outpatients with AECOPD. COPD: Journal of Chronic Obstructive Pulmonary Disease. 2018;15(5):479-488

59. Alma H, de Jong C, Tsiligianni I, Sanderman R, Kocks J, van der Molen T. Clinically relevant differences in COPD health status: systematic review and triangulation. European Respiratory Journal. 2018;52(3):1800412.

60. Stridsman C, Müllerova H, Skär L, Lindberg A. Fatigue in COPD and the impact of respiratory symptoms and heart disease - a population-based study. COPD: Journal of Chronic Obstructive Pulmonary Disease. 2013;10(2):125-32.

61. Cella D, Yount S, Sorensen M, Chartash E, Sengupta N, Grober J. Validation of the

497 Functional Assessment of Chronic Illness Therapy Fatigue Scale relative to other 498 instrumentation in patients with rheumatoid arthritis. The Journal of Rheumatology. $499 \quad 2005 ; 32(5): 811-9$.

500 62. Goligher EC, Pouchot J, Brant R, Kherani RB, Aviña-Zubieta JA, Lacaille D, et al. 501 Minimal clinically important difference for 7 measures of fatigue in patients with systemic 502 lupus erythematosus. The Journal of rheumatology. 2008;35(4):635-42.

503 63. Turner D, Schünemann HJ, Griffith LE, Beaton DE, Griffiths AM, Critch JN, et al. 504 The minimal detectable change cannot reliably replace the minimal important difference. 505 Journal of clinical epidemiology. 2010;63(1):28-36.

506 64. Goodwin LD, Leech NL. Understanding correlation: Factors that affect the size of r. 507 The Journal of Experimental Education. 2006;74(3):249-66.

508 65. Garrison C, Cook C. Clinimetrics corner: the Global Rating of Change Score (GRoC) 509 poorly correlates with functional measures and is not temporally stable. Journal of Manual 510 \& Manipulative Therapy. 2012;20(4):178-81. 
511 66. Miravitlles M, Ferrer J, Baró E, Lleonart M, Galera J. Differences between physician

512 and patient in the perception of symptoms and their severity in COPD. Respiratory medicine. $513 \quad 2013 ; 107(12): 1977-85$.

514 67. Cella D, Lai J-S, Stone A. Self-reported fatigue: one dimension or more? Lessons 515 from the Functional Assessment of Chronic Illness Therapy-Fatigue (FACIT-F) 516 questionnaire. Supportive Care in Cancer. 2011;19(9):1441-50.

517 68. Criner GJ, Bourbeau J, Diekemper RL, Ouellette DR, Goodridge D, Hernandez P, et 518 al. Prevention of acute exacerbations of COPD: American college of chest physicians and 519 Canadian thoracic society guideline. Chest. 2015;147(4):894-942.

520 69. Schünemann HJ, Puhan M, Goldstein R, Jaeschke R, Guyatt GH. Measurement 521 properties and interpretability of the Chronic respiratory disease questionnaire (CRQ). 522 COPD: journal of chronic obstructive pulmonary disease. 2005;2(1):81-9.

523 70. Alma H, de Jong C, Jelusic D, Wittmann M, Schuler M, Kollen B, et al. Baseline 524 health status and setting impacted Minimal Clinically Important Differences in COPD: an 525 explorative study. Journal of clinical epidemiology. 2019;116:49-61.

526 TABLES:

527 Table 1: Sample characterisation $(\mathrm{n}=70)$.

\begin{tabular}{|c|c|c|c|}
\hline Characteristics & $\begin{array}{l}\text { Patients included } \\
\quad \mathbf{n}=53(75.7 \%)\end{array}$ & $\begin{array}{c}\text { Drop-outs } \\
\text { n=17 }(24.3 \%)\end{array}$ & p-value \\
\hline Age, years & $68.4 \pm 7.6$ & $67 \pm 11.3$ & 0.568 \\
\hline Gender, male n $(\%)$ & $42(79.2)$ & $12(70.6)$ & 0.460 \\
\hline BMI, $\mathbf{k g} / \mathbf{m}^{2}$ & $25.6 \pm 4.3$ & $27.2 \pm 4.8$ & 0.217 \\
\hline Smoking status, $\mathbf{n}(\%)$ & & & 0.638 \\
\hline Current & $9(17)$ & $6(35.3)$ & \\
\hline Former & $35(66)$ & $7(41.2)$ & \\
\hline Never & $9(17)$ & $4(23.5)$ & \\
\hline Packs/year & $40.5[26.4-64]$ & $22[13.3-50.4]$ & 0.057 \\
\hline Exacerbations/year ${ }^{1}, \mathbf{n}$ & $1[0-1]$ & $1[0-2]$ & 0.139 \\
\hline AECOPD hospitalisations ${ }^{1}, \mathrm{n}(\%)$ & $4(7.5)$ & $4(23.5)$ & 0.072 \\
\hline Duration of hospitalisations, days & $8.2 \pm 7.1$ & $10.4 \pm 9.4$ & 0.606 \\
\hline
\end{tabular}




\begin{tabular}{|c|c|c|c|}
\hline COPD-related emergencies ${ }^{1}, \mathrm{n}(\%)$ & $18(34)$ & $7(41.2)$ & 0.589 \\
\hline \multicolumn{4}{|l|}{ Lung function (post-bronchodilator) } \\
\hline $\mathbf{F E V}_{1}, \mathbf{l}$ & $1.3 \pm 0.5$ & $1.4 \pm 0.5$ & 0.404 \\
\hline $\mathrm{FEV}_{1}, \%$ predicted & $48.1 \pm 17.4$ & $56.5 \pm 19.6$ & 0.101 \\
\hline $\mathrm{FEV}_{1} / \mathrm{FVC}, \%$ & $49.1 \pm 14.1$ & $55.9 \pm 13$ & 0.077 \\
\hline GOLD stages, n (\%) & & & 0.905 \\
\hline $\mathbf{I}$ & $5(9.4)$ & $2(11.8)$ & \\
\hline II & $19(35.8)$ & $7(41.2)$ & \\
\hline III & $23(43.4)$ & $7(41.2)$ & \\
\hline IV & $6(11.3)$ & $1(5.9)$ & \\
\hline GOLD groups, n (\%) & & & 0.106 \\
\hline $\mathbf{A}$ & $8(15.1)$ & $4(23.5)$ & \\
\hline $\mathbf{B}$ & $34(64.2)$ & $6(35.3)$ & \\
\hline $\mathbf{C}$ & $0(0)$ & $0(0)$ & \\
\hline $\mathbf{D}$ & $11(20.8)$ & $7(41.2)$ & \\
\hline CCI, n (\%) & & & 0.389 \\
\hline Mild (1-2 points) & $7(13.2)$ & $1(5.9)$ & \\
\hline Moderate (3-4 points) & $30(56.6)$ & $8(47.1)$ & \\
\hline Severe ( $\geq 5$ points) & $16(30.2)$ & $8(47.1)$ & \\
\hline \multicolumn{4}{|l|}{ Medication, n (\%) } \\
\hline \multicolumn{4}{|l|}{ Bronchodilators } \\
\hline SABA & $7(13.2)$ & $1(5.9)$ & 0.360 \\
\hline SAMA & $2(3.8)$ & $0(0)$ & 0.393 \\
\hline LABA & $6(11.3)$ & $5(29.4)$ & 0.102 \\
\hline LAMA & $16(30.2)$ & $10(58.8)$ & 0.065 \\
\hline LAMA/LABA combination & $16(30.2)$ & $4(23.5)$ & 0.597 \\
\hline ICS & $9(17)$ & $1(5.9)$ & 0.226 \\
\hline ICS/LABA combination & $23(43.3)$ & $7(41.2)$ & 0.872 \\
\hline ICS/LABA/LAMAcombination & $1(1.9)$ & $0(0.0)$ & 0.273 \\
\hline LTRA & $2(3.8)$ & $2(11.8)$ & 0.217 \\
\hline Xanthines & $10(18.9)$ & $2(11.8)$ & 0.499 \\
\hline
\end{tabular}




\begin{tabular}{|c|c|c|c|}
\hline Expectorants & $5(9.4)$ & $1(5.9)$ & 0.649 \\
\hline Antibiotics & $1(1.9)$ & $0(0)$ & 0.606 \\
\hline mMRC, points & $2[1-3]$ & $2[1-3]$ & 0.733 \\
\hline CAT, points & $16.9 \pm 7.5$ & $16.2 \pm 9.2$ & 0.736 \\
\hline \multicolumn{4}{|l|}{ SGRQ, points } \\
\hline Symptoms & $55 \pm 20.5$ & $45.8 \pm 20.1$ & 0.112 \\
\hline Activities & $64.8 \pm 20.9$ & $50.3 \pm 27.8$ & 0.060 \\
\hline Impact & $36.6 \pm 19.8$ & $27.8 \pm 19.1$ & 0.114 \\
\hline Total & $48.2 \pm 18.6$ & $37.7 \pm 19.8$ & 0.050 \\
\hline FACIT-FS, points & $33.3 \pm 10$ & $37.7 \pm 12.8$ & 0.151 \\
\hline No relevant fatigue $(>43)$, n $(\%)$ & $19(17)$ & $5(29.4)$ & \\
\hline Relevant fatigue $(\leq 43), \mathrm{n}(\%)$ & $44(83)$ & $12(70.6)$ & 0.214 \\
\hline Modified-FACIT-FS & $21.2 \pm 7.4$ & $22.7 \pm 7.7$ & 0.496 \\
\hline CIS-FS, points & $36.9 \pm 12.8$ & $32.7 \pm 13.9$ & 0.258 \\
\hline Normal fatigue ( $\leq 26), \mathrm{n}(\%)$ & $9(17)$ & $6(35.3)$ & \\
\hline Mild fatigue, (27-35), n (\%) & $12(22.6)$ & $5(29.4)$ & 0.153 \\
\hline Severe fatigue $(\geq 36)$, n $(\%)$ & $32(60.4)$ & $6(35.3)$ & \\
\hline
\end{tabular}

528 529

530

531

532

533

534

535

536

537

538

539

540

541

Notes: Values are presented as mean \pm standard deviation or median [interquartile range], unless otherwise stated. ${ }^{1}$ in the past-year; * $\mathrm{p}<0.05$

Legend: PR - pulmonary rehabilitation; BMI - body mass index; AECOPD - acute exacerbation of chronic obstructive pulmonary disease; $\mathrm{FEV}_{1}$ - forced expiratory volume in one second; FVC - forced vital capacity; GOLD - Global Initiative for Chronic Obstructive Lung Disease; CCI - Charlson comorbidity index; SABA - short-acting beta-agonists; SAMA - short-acting muscarinic antagonist; LABA - long-acting beta-agonists; LAMA - long-acting muscarinic antagonist; ICS - inhaled corticosteroid; LRTA - leukotriene receptor antagonist; mMRC - modified medical research council questionnaire; CAT - COPD assessment test; SGRQ - St George's Respiratory Questionnaire; FACIT-FS - Functional assessment of chronic illness therapy fatigue subscale; CIS-FS - Checklist of individual strength fatigue subscale. 
542 Table 2: Patient-reported outcome measures before and after the community-based 543 pulmonary rehabilitation programme $(n=53)$.

\begin{tabular}{|c|c|c|c|c|c|c|}
\hline PROM (points) & Baseline & Post-PR & $\Delta$ & $95 \% \mathrm{CI}$ & p-value & ES \\
\hline CAT & $16.9 \pm 7.5$ & $13.0 \pm 6.9$ & $-3.9 \pm 6.7$ & -5.8 to -2.0 & $<0.001^{*}$ & -0.54 \\
\hline \multicolumn{7}{|l|}{ SGRQ } \\
\hline Symptoms & $55 \pm 20.5$ & $41.1 \pm 20.5$ & $-13.9 \pm 21.5$ & -19.8 to -7.9 & $<0.001 *$ & -0.68 \\
\hline Activities & $64.8 \pm 20.9$ & $57.8 \pm 23.5$ & $-7.0 \pm 11.6$ & -10.2 to -3.8 & $<0.001 *$ & -0.31 \\
\hline Impact & $36.6 \pm 19.8$ & $30.4 \pm 18.7$ & $-6.2 \pm 12.0$ & -9.5 to -2.8 & $<0.001^{*}$ & -0.32 \\
\hline Total & $48.2 \pm 18.6$ & $40.6 \pm 18.1$ & $-7.6 \pm 10.4$ & -10.5 to -4.7 & $<0.001 *$ & -0.41 \\
\hline FACIT-FS & $33.3 \pm 10$ & $36.9 \pm 8.8$ & $3.7 \pm 7.1$ & 1.7 to 5.6 & $<0.001^{*}$ & 0.38 \\
\hline $\begin{array}{l}\text { Modified-FACIT- } \\
\text { FS }\end{array}$ & $21.2 \pm 7.4$ & $24.0 \pm 6.9$ & $2.7 \pm 5.5$ & 1.2 to 4.3 & 0.001 & 0.38 \\
\hline CIS-20 FS $(n=52)$ & $36.9 \pm 12.8$ & $31.1 \pm 13.4$ & $-5.8 \pm 10.2$ & -8.7 to -3.0 & $<0.001 *$ & -0.44 \\
\hline
\end{tabular}

Notes: Values are presented as mean \pm standard deviation. ${ }^{*} \mathrm{p}<0.05$

Legend: PROM - Patient-reported outcome measure; PR - pulmonary rehabilitation; $\triangle$ - mean change; ES - Effect sizes: $95 \% \mathrm{CI}$ 95\% confidence interval; CAT - COPD assessment test; SGRQ - St George's Respiratory Questionnaire; FACIT-FS - Functional 
563 Table 3: Anchor and distribution-based methods used to compute the minimal clinically 564 important difference of fatigue patient-reported outcome measures.

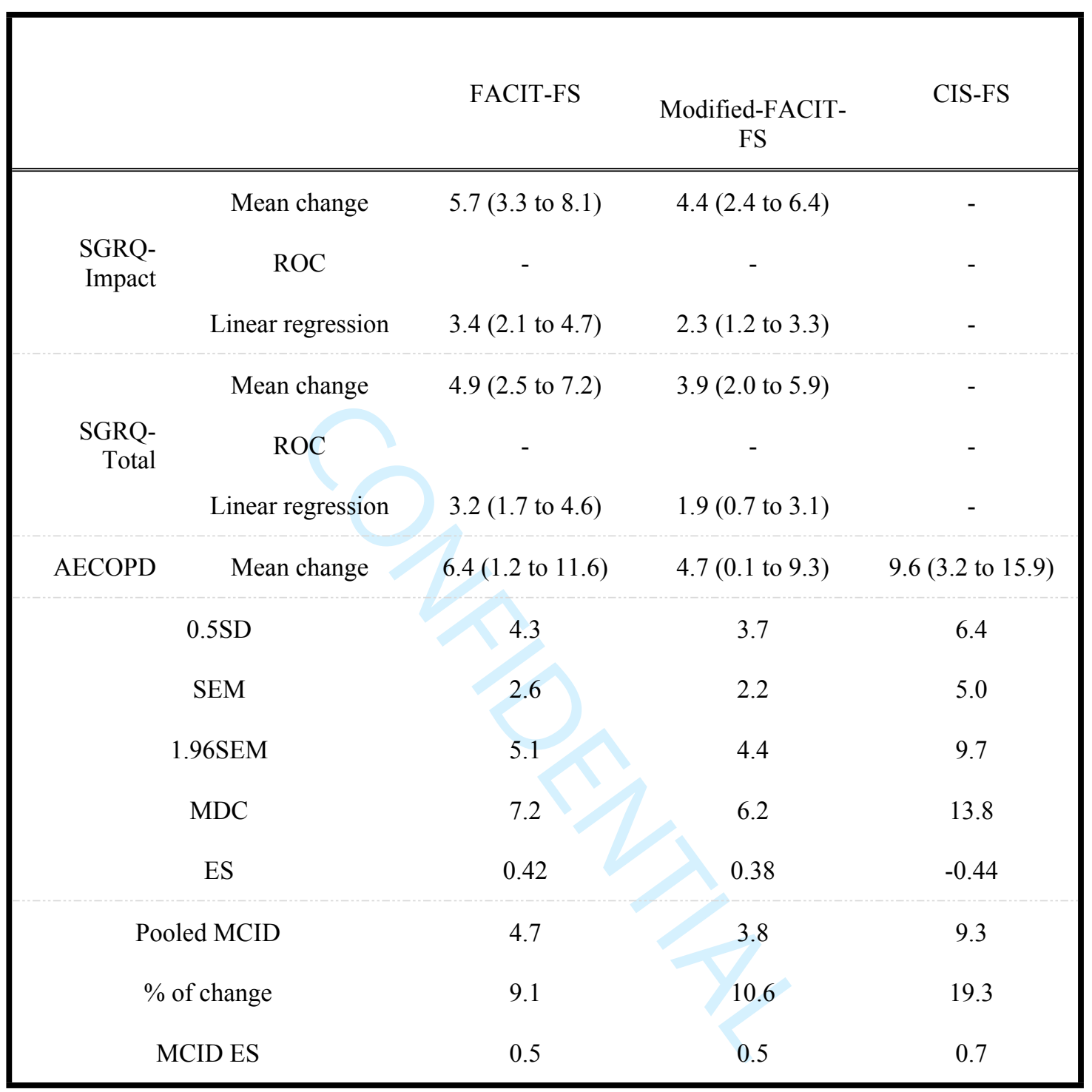

565

566 Notes: Values are presented as mean and 95\% confidence intervals. \% of change was computed within each scale range. The MCID ES 567 are compute as the MCID value divided by the pooled SD.

568 Legend: FACIT-FS - Functional assessment of chronic illness therapy fatigue subscale; CIS-20 FS - Checklist of individual strength

569 fatigue subscale; SGRQ - St George's Respiratory Questionnaire; ROC - Receiver operating characteristic curves; SD - standard

570 deviation; SEM - standard error of measurement; MDC - minimal detectable change; ES - effect size; MCID - minimal clinically 571 important difference. 


\section{FIGURE LEGEND:}

576 Figure 1: Flow diagram of participants recruited and included in the study. COPD - Chronic 577 obstructive pulmonary disease; PR - pulmonary rehabilitation; AECOPD - acute 578 exacerbation of chronic obstructive pulmonary disease.

579 Figure 2: Linear regression between changes in the A) Functional Assessment of Chronic 580 Illness Therapy Fatigue Subscale (FACIT-FS) and changes in the St George's Respiratory 581 Questionnaire (SGRQ)-impact; B) FACIT-FS and changes in the SGRQ-total score; C) 582 modified-FACIT-FS and changes in the SGRQ-impact; D) modified-FACIT-FS and 583 changes in the SGRQ-total score $(n=53)$.

584 Figure 3: Plots of the pooled minimal clinically important differences (MCID) for the: A) 585 Functional Assessment of Chronic Illness Therapy Fatigue Subscale (FACIT-FS); B) 586 modified-FACIT-FS; C - Checklist of individual strength fatigue subscale (CIS-FS). The 587 plots represent the MCID estimates derived in this study, and where appropriated the 588 estimates include the 95\% confidence interval ( $n=53)$. AECOPD - acute exacerbation of 589 chronic obstructive pulmonary disease; SGRQ - St. George Respiratory Questionnaire; SD 590 - standard deviation; SEM - standard error of measurement; MDC - minimal detectable 591 change. 


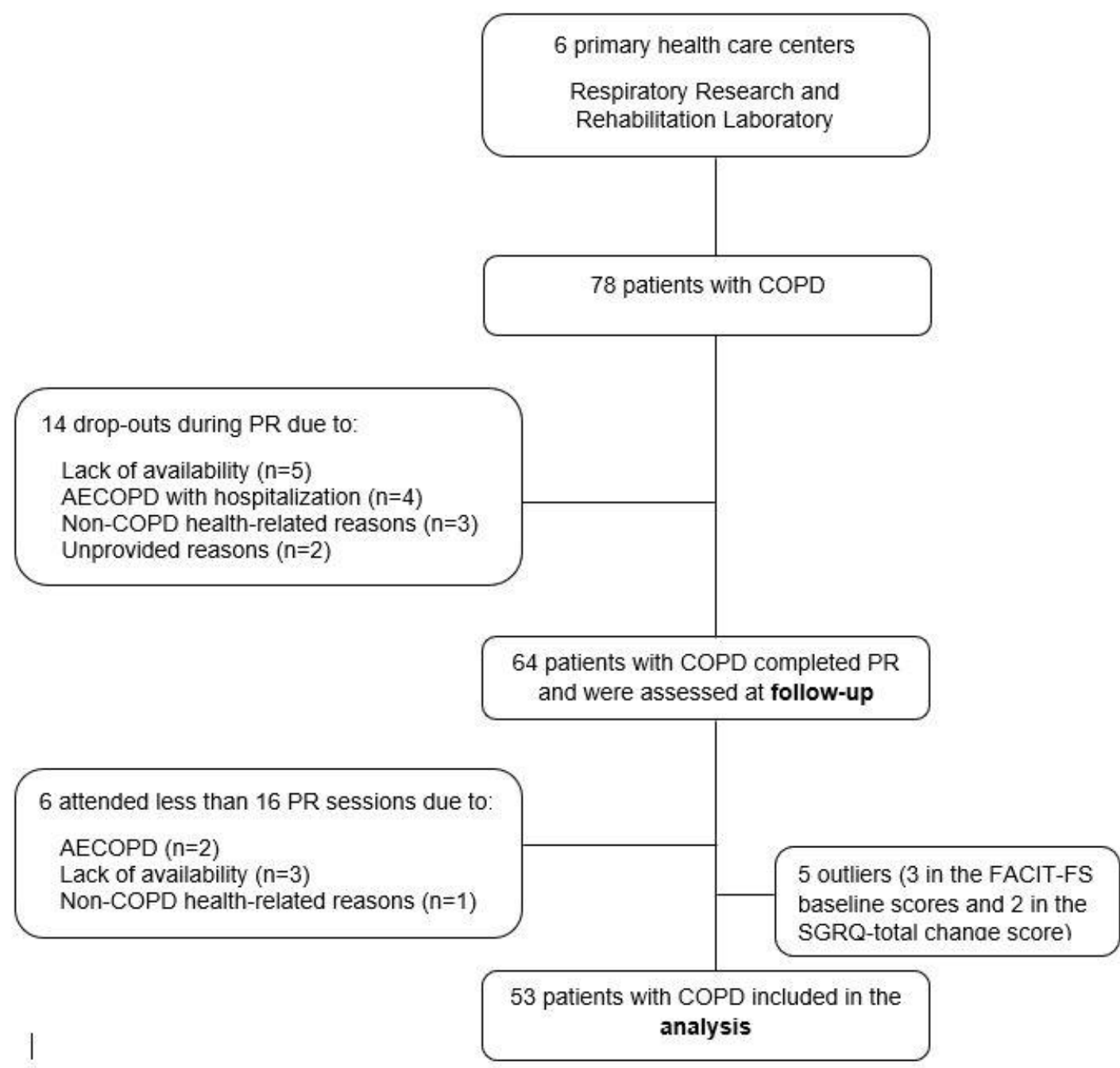




\section{FACIT-FS}
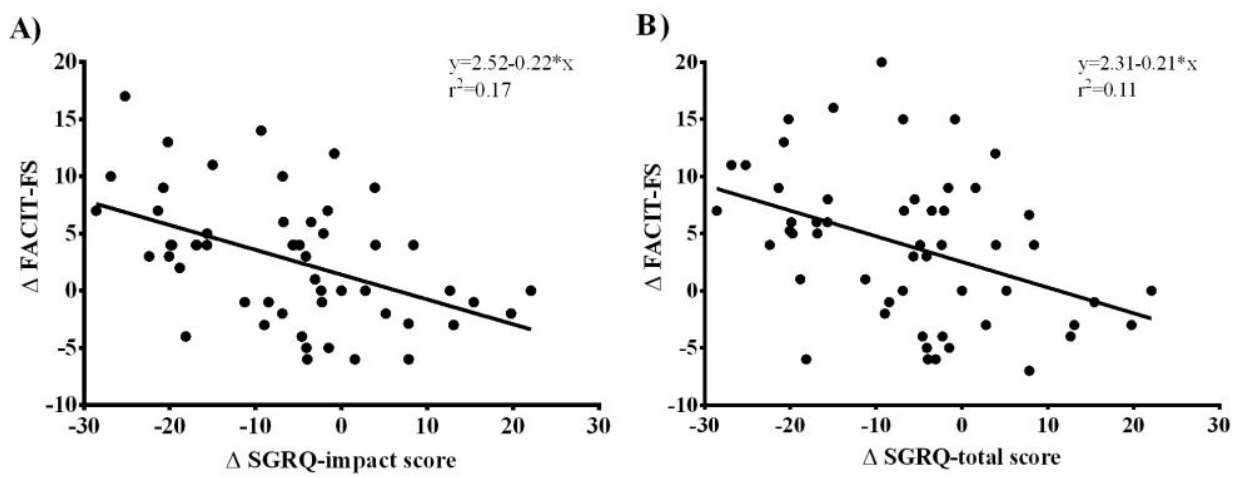

\section{Modified FACIT-FS}
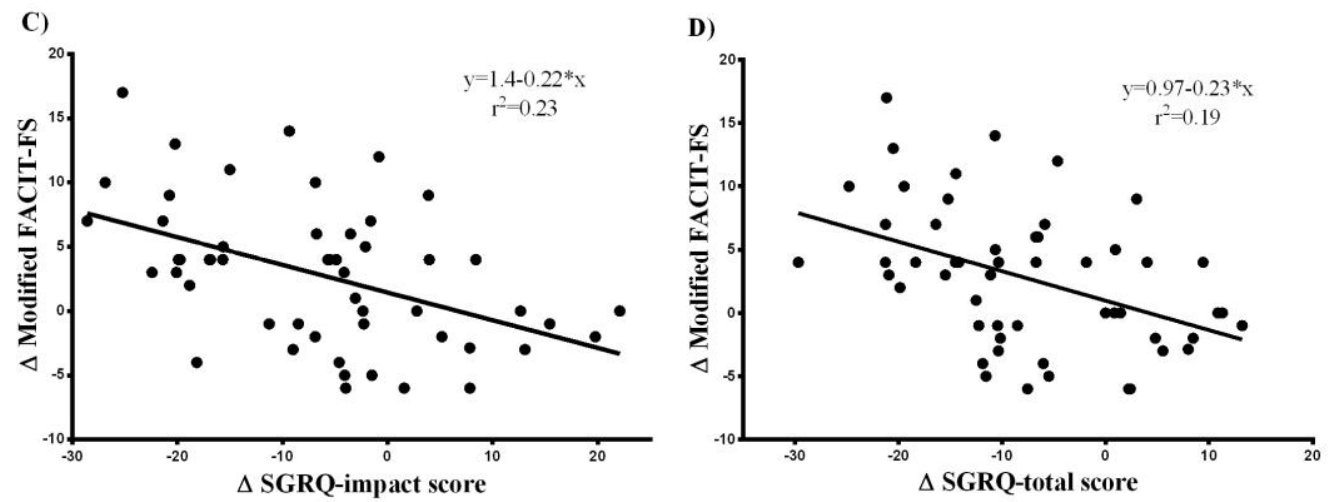
A)

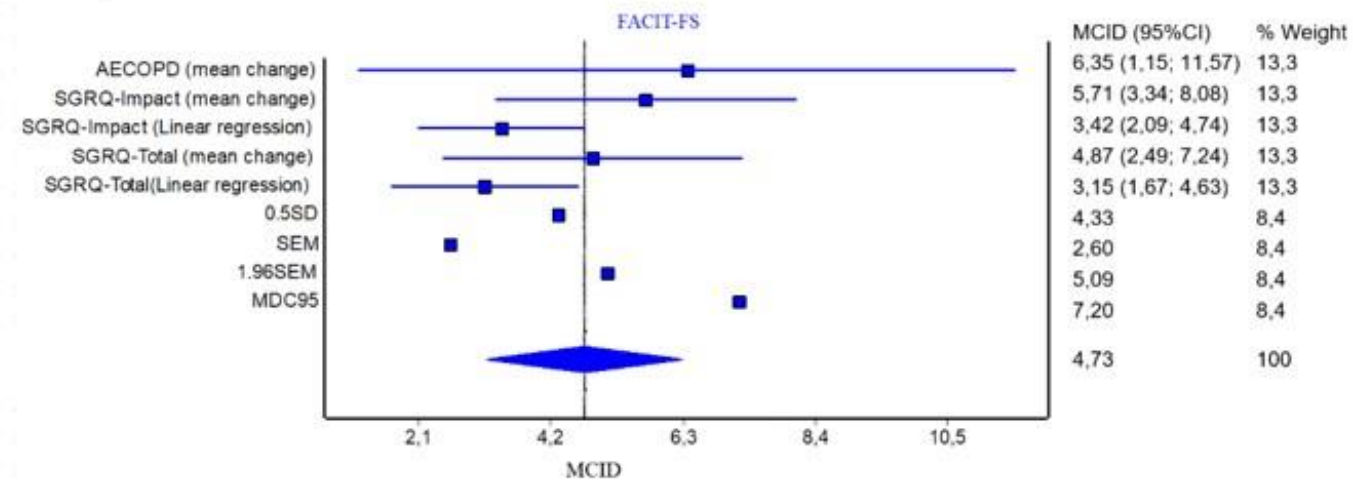

B)

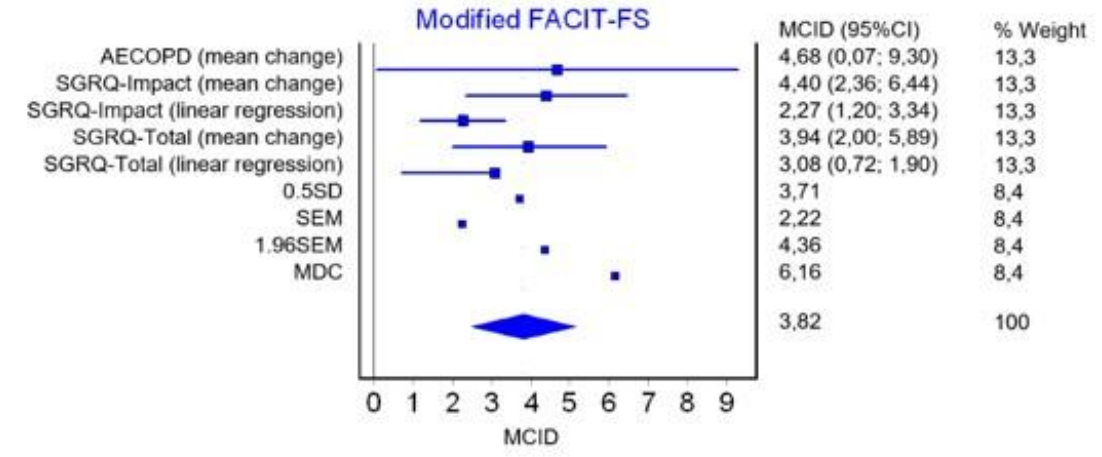

C)

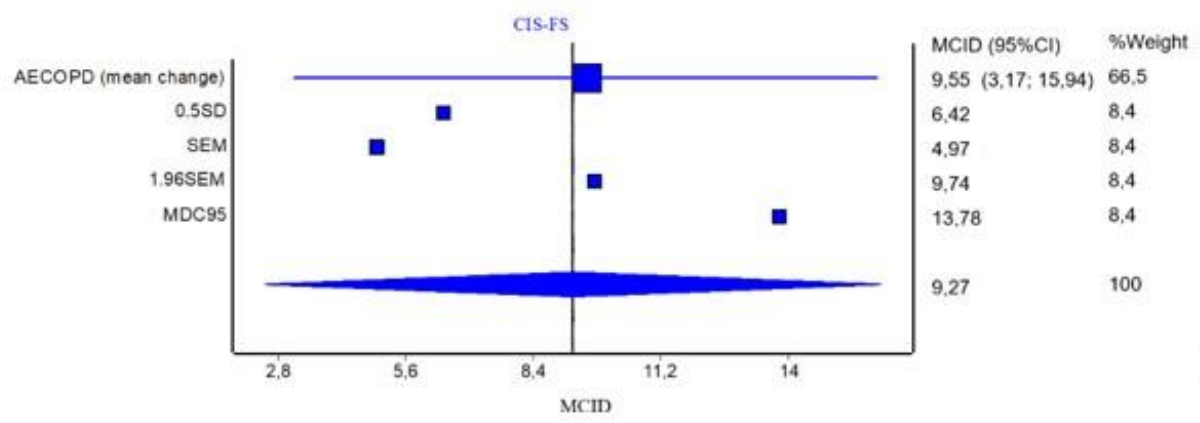

